\title{
Guidelines for Designing Distance Learning Courses via Moodle to Enhance Students Satisfaction and Achievements
}

\author{
Hassan Abuhassna, Noraffandy Yahya, Megat Aman Zahiri Megat Zakaria, Qusay Al-Maatouk, and \\ Fareed Awae
}

\begin{abstract}
This research aims to develop guidelines on designing Distance Learning (DL) courses through Moodle system to enhance student's satisfaction and academic achievements in online learning environments. This research consists of two main phases; phase one aims to develop a DL course based on ADDIE course design strategy via Moodle system; phase two was the interview part, wherein a qualitative approach was employed to give an inclusive insight into this matter. Ten participants were interviewed. The interview group consists of two, three, and four participants in each group. Based on the interview results the researcher noted that student autonomy or self-educating is the key point for the students to overcome the challenges during the DL experience. The interviewees commented that this experience had improved their satisfaction in several ways. In conclusion, this experience provided them with a platform where they can be more active and collaborative in their own learning process.
\end{abstract}

Index Terms-Online learning, moodle, distance learning, e-learning.

\section{INTRODUCTION}

DL courses offer integrated settings of various technologies to assist both instructors' and students' learning via the internet. The aim of such tools is to improve and complete the traditional way of teaching, and maybe replace it at times. There have been numerous research and frameworks designed for analyzing web-based courses from both institutional and pedagogical perspectives [1]-[5]. This research provides instructions on what elements to consider and how they might be used when instructors and administrators are considering utilizing DL courses in teaching and learning. One of the most important elements when designing DL courses is the flexibility of the course, and how students would be able to utilize it. DL flexibility is related to student's background regarding the internet and LMS system [1], [2]. DL flexibility is commonly referred to as the extent to which the course is to assist a user in accomplishing a task [6]. Different methods could be used to examine the students background and experiences of online

Manuscript received July 9, 2021; revised August 26, 2021.

Hassan AbuHassna, Norafandy Yahya, Megat Aman Zahiri Megat Zakaria, and Fareed Awae are with Faculty of Social Sciences \& Humanities, School of Education, Universiti Teknologi Malaysia, 81310, UTM Skudai, Johor, Malaysia (e-mail: mahassan@utm.my, fandymcl@gmail.com, megataman@utm.my, afareed@utm.my).

Qusay Al-Maatouk is with School of Technology, Asia Pacific University of technology and Innovation, 57000, Bukit Jalil, Technology Park Malaysia Kuala Lumpur, Malaysia (e-mail: Qusay@staffemail.apu.edu.my). learning DL courses, such as interviews, observation, expert reviews, and questionnaires [7]. The user interface design is a very essential element in DL course that will exhibit natural communication and collaboration between both the course itself and students [7].

Students' background and experience about online learning is a critical factor during this process, as revealed in prior research that there are employment issues, such as the lack of skilled instructors, facilities, and infrastructure. Other factors include learner's willingness to learn online, along with learners' resistance to accept online learning settings such as Learning Management System (LMS) as an educational setting [8]. Nevertheless, learners demand continued to rise, spreading to audiences worldwide due to its extraordinary functionality, accessibility, and eventual flexibility [8]. There have been constant concerns among educational institutions about the quality of online learning when compared to traditional learning environments. In their investigation, Paechter and Maier [9], Panyajamorn and Suthathip et al. [10] found that Austrian students are continuing to favor Face-to-Face learning settings due to the direct communication, in conjunction with the social relations preservation.

Accordingly, this research aims to develop guidelines on designing DL courses through Moodle system to enhance academic achievements and student's satisfaction in online learning environments. Consequently, this proposed guideline would have to be employed for both decision makers and tutors in the industry of online learning from the perspective of employing online platforms to help improve learners' education experience via online platforms. Taking into consideration these terms and conditions, our main issue was: how could we improve online learning experience among students by designing a web-based course in connection with their satisfaction and academic achievements?

\section{OBJECTIVES OF THE STUDY}

This research is aimed to:

- To develop a DL course based on ADDIE and Transactional Distance Theory (TDT).

- To investigate students' reflections towards DL courses through interviewing them after going through DL courses for their classes.

- To design and integrate a guideline on designing DL courses through Moodle system to enhance student's 
academic achievements and satisfaction in online learning environments.

\section{BACKGROUND AND ITERATURE REVIEW}

E-Learning has several definitions and purposes but in short, it is synonymous with electronic learning tools, such as the computer and the internet. That means learning indirectly from lecture materials, books, or face-to-face from the instructor but also in an electronic format, such as YouTube videos, recorded and live videos [11] The most widespread forms are computer-based instruction and DL courses or online classes, in both synchronous and asynchronous formats. With the emergence of modern technology, lessons can also be carried anywhere anytime at their own pace. This research investigates some concepts that are related to online learning and are based on students own experiences recorded by way of interview. These concepts include online learning, DL, technologies in education, and challenges of e-learning in Palestine Universities. [11] defined online learning as the utilization of both digital technologies and the internet to create experiences that teach our trainees or students at their own place and time. DL courses through e-learning or Moodle incorporates the use of certain technologies via the internet to create materials and environments for teaching and learning, and at the same time control and manage courses in educational institutions [12]. Although considerable discussion regarding a general definition of the e-learning term has been discussed and argued through the years, there are some existing definitions such as [13] who have tended to reveal the interest and specialization of the scholars.

In certain definitions, e-Learning includes more than simply offering online classes. For example, Oblinger and Hawkins et al. [14] stated that e-Learning has been transformed from a fully online class to utilizing technology to provide only part or all the class in an independent way despite the place and time. Moreover, the European Commission [15] defines e-Learning as the utilization of the Internet in addition to new multimedia technologies to enhance the quality of learning by facilitating access to services and information, along with distant collaboration and exchanges. The next section discusses the meaning of Moodle technology.

E-learning quality has been investigated by Tseng [16] who recommended that the attractiveness of the software to students is the most important measure of the effectiveness of e-learning. Additionally, decreasing the instructor's response time to a reply to the student's query could enhance the quality of the experience leading to e-learning effectiveness. A study carried out by Salter [17] to verify the effectiveness of e-learning has discovered that e-learning impact effectively increases the students' knowledge. However, this study has not been able to reveal whether e-learning has the ability to effectively enhance the professional practice or skills of the students. Furthermore, Noesgaard and Orngreen [18] has found that it is difficult to guarantee the effectiveness of e-learning to enhance the teaching and learning process, as the instructor of the course cannot employ several strategies and methods of teaching as required. E-learning environments could be cost and time effective and could be effortlessly utilized to fulfil the learning requirements. In addition, e-learning environments offers more freedom to learners to be more entertained and interactive [19].

Johnson [20] claimed that e-learning environments could be more effective than face-to-face environments for providing learners with updated knowledge to accomplish learning objectives. Similarly, Rosenberg [21] claimed that e-learning environments are at least as effective as face-to-face environments. E-learning significantly increases the access to learning anywhere and anytime, improves the quality of teaching and learning, and reduces the learning cost [22]. E-learning environments are a potential replacement for face-to-face environments [23]. E-learning environments are comparatively less expensive than face-to-face environments. In addition, it is student centered method that enables learners to obtain skills in various ways, for instance video, text, image, etc. [24]. A survey has been conducted on e-learning environments by [25] which revealed most of the participants commented that e-learning is crucial and valuable to meet their needs. E-learning environments enable students to control the content of the course, fix time scheduling, determine learning pace, and select the most suitable media to meet their learning objects and to manage the course materials [26].

\section{COURSE DESIGN APPROACH}

This part of this study discusses the methodology used to design the DL course via Moodle platform. There are numerous instructional systems design models, the vast majority of which are based on popular ones like, for example, the ADDIE model, which is diagrammed in (Fig. 1). The course was designed based on ADDIE model which is an instructional system design. This model includes five main phases: Analyse, Design, Develop, Implement, and Evaluate. Adapting existing models to correspond to needs is more sensible than progressing without any plan [27]. Nevertheless, flexible approach is required to choose and adopt a model to a certain situation [28]. Nevertheless, the design phase was originally built based on Moore transactional distance theory (TDT).

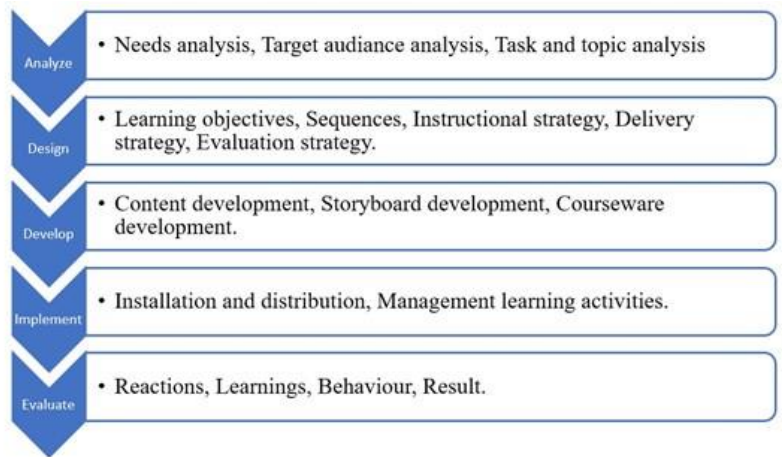

Fig. 1. ADDIE Model phases adopted from Russell Watson (1981).

\section{A. Instructional System Design (ISD)}

The researcher applied a systematic instructional system design ISD approach known as ADDIE (See Fig. 1). ADDIE 
is a sequence of five stages that must be followed logically for each phase to provide input for the following phase [29]. ADDIE provides a strategy to create and design instructional courses in education. In the process, each phase is informed by rapid prototyping to get the instructors, students, and any targeted users feedback needed for the next phase [30]-[33]. This ISD Model has been implemented with some improvements on the design phase to meet with Moore's transactional distance theory, which is done by implementing the TDT channels of interaction. Moore [33], [34] described three types of interaction in online learning as he summarized the online learning interaction: Student and the study subject or content interaction, Interaction between the instructor and the student, and Interaction between one student and his her classmates, individually or in-group, with the presence of the educator or without it. Described below are the five stages in the ADDIE process:

\section{B. Analysis Phase}

As the first and the most significant phase, a needs analysis must be implemented at the beginning of any development attempt to decide whether the course is required to fill a gap in the audience knowledge, skills, and to decide whether the course design is the best way to deliver the course. In this regard, the researcher collected the data from the first phase of the study (assessment phase), topic content, learning outcomes, and student background. Target audience analysis is a crucial step. The course design and delivery of the DL course were influenced by the outcomes of the student's characteristics, and their background, geographical provenience, technology access, and learning context.

\section{Design Phase}

Design is a systematic way to specify learning outcomes. In the design phase, learning materials that incorporate learning activities, quizzes, tests, and learning contents have been developed by a reference to the Curriculum Book of Education Psychology according to the topics mentioned in the book. In this phase, the researcher applied the TDT of Moore. Moore termed transactional distance as a particular function of interaction among the three main variables, which are autonomy, course structure, and dialogue [33], [34].

\section{The Theoretical Basis on Designing the DL Course}

Before considering the treatment DL course, a proper framework was chosen to design the DL course. The theoretical base of the course used Moore's TDT. Moore theorizes that the dialogue is created among the instructors and their pupils, and is essential for the structure formation, which in turn illustrates the flexibility or rigidity of the system, including its potential to serve individual pupils' demands. The interaction between these three variables may be summed up as follows:

- When the course structure increases, the dialogue decreases, and the transactional distance increases

- When the dialogue increases, the course structure will decrease than the transactional distance decreases

- When the autonomy of the students increases, the course structure decreases, then the transactional distance decreases.

- When the course structure decreases, the autonomy of the students increases then the transactional distance decreases.

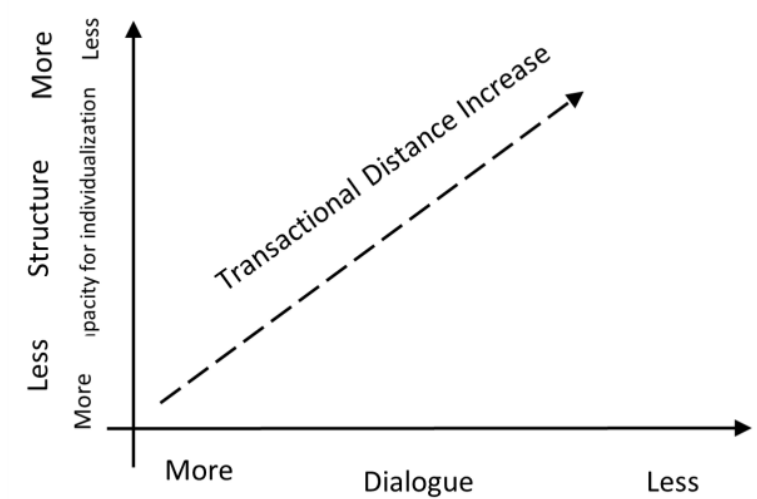

Fig. 2. From Michael G. Moore's (2006) presentation to European distance education network.

\section{E. Transactional Distance Theory Implementation}

As shown in Fig 2, TDT theory has been critiqued and revised by numerous researchers within and without the field of online learning. Several significant researches in distance and online learning have studied TD either through comparing it in conjunction with further theories [33]; concentrating on course design application in decreasing distance transactional distance [33], [34]; or else examining its implementation as a measurement of the satisfaction of both instructor and student [35]-[42]. Besides the rationality of its claims [43]-[45] in forecasting outcomes, [46] claimed that it is reliable and consistent. Nevertheless, no research has previously exclusively utilized transactional distance theory as its theoretical foundation [47]-[52]. TDT presents the authors with a chance to investigate how the student interacts with the course based on his/her communication with the main entities in the course. Basically, there are four different interaction types, i.e., communication with the teacher (Student-Lecturer), communication with other learners during the course (Student-Student), communication with the material of the course (Student-course), then communication with the technology providing the course itself (Student-Content).

\section{1) Student-instructor interaction}

This communication is a reference to the interaction between learners with the instructor of the course, and other individuals who are directly participating in the facilitation or the course delivery. The communication is typically a two-way procedure by Moore and Kearsley [53], in which both sides are involved in a respectful, common 'dialogue'. In this case, communication does not necessarily have to be vocal in nature.

\section{2) Student-student interaction}

This communication comes in many shapes, although it is mostly two-way communications such as the interaction between two learners, as well as multidirectional such as group discussions, whereby one learner interacts with all the other of the class or group. Such interaction, which could exist with and without a teacher involved, is just as crucial to learning, particularly in distance learning environments, for the reason that through it, learners have the opportunity to 
exchange ideas and concepts that are relevant to the course.

\section{3) Student-content interaction}

This represents a one-way communication between the learner and the course. It comprises breaking down the course structure into controllable parts and integrating it. Along with this communication, students get knowledge by adding new information to whatever they have learned before, in short, it comprises learner's capability to obtain or transfer information whether from classes, video sources, texts over an internal moral dialog [44] that is comprised of speaking to oneself regarding the concepts, ideas, and information related to the course or subject that is being learned.

\section{4) Students-interface interaction}

This relates to the learner's communication with the course delivery technology involving learners comfort level with technology in general including learning management systems (LMS), internet, software programs, and computers, which might include another software such as video conferencing software and PowerPoint. However, most courses simply require learners to have the ability to manage a computer to gain access to course material through (LMS) or E-learning. That kind of communication is extremely crucial since some courses could require learners to produce a podcast, presentation video, or else log into a video conferencing session or webinar.

\section{F. Development Phase}

Development Phase is the real production and assembly of materials of the intended system at the design stage. This phase begins once the design phase has been completed, with content that had been produced in this phase. The content was varied significantly, depending upon the resources that are available. For instance, some of the content might comprise only simpler materials (i.e., ones with little or no multimedia or interactivity, for example structured PDF files) that can be merged with supplementary materials (e.g., video files or audio), tests and assignments. Hence, the content of the course was based on the Education Psychology course book in the UCAS.

\section{G. The Application of the DL Course for Education Psychology - CF201 through Moodle}

The education psychology course (CF201) is offered as a compulsory course for undergraduate students at the faculty of education studies, UCAS. Thus, this course has been offered on a face-to-face basis. The course discusses the main concepts of education psychology. The process of incorporating the education psychology course into the DL course progressed by obtaining the syllabus, content, and the outline of the course from the instructor of the course. The instructor of this course was assigned to teach this course, with the involvement of the researcher for training and monitoring the process of the treatment through Moodle. By using multi-sources, such as PowerPoint slides, videos, graphs, PDF files, using Moodle as a mean throughout the duration of course ( 8 weeks), the details of the incorporation of the DL course. The content of the DL course was arranged on a weekly basis according to the standard curriculum. Accordingly, all the course topics were presented clearly followed by the activities and quizzes.

\section{H. Implementation Phase}

Implementation phase is where the developed course is put into action, and the final product is presented to the target audience. The implementation phase is consisted of two main steps according to [54], which are installation and distribution, along with Management learning activities. Therefore, the computer lab in UCAS was set up and prepared before the learning period has started. This is to ensure that computers and tools are in place and in good condition, and internet connection was tested to be live and functioning. Moreover, learners were asked to create and signup in the Moodle system during the first face-to-face meeting with an assistant from the lab technician. Alternatively, all the course activities were designed to be applied to groups, with the intention to give the learners the chance to work collaboratively. As characterized by [33], the scope of any educational course ensures that the student and teacher can reply and answer each other. This involves the studied content, the teacher's educational philosophy, the teacher and student personalities, and by elements of the environment that revolve around both, elements that comprise communication. Ten groups were created, each group consisted of five learners. Throughout the group activities, learners had to work closely with their group members to accomplish their tasks and assignments. However, they were asked to work on their quizzes individually.

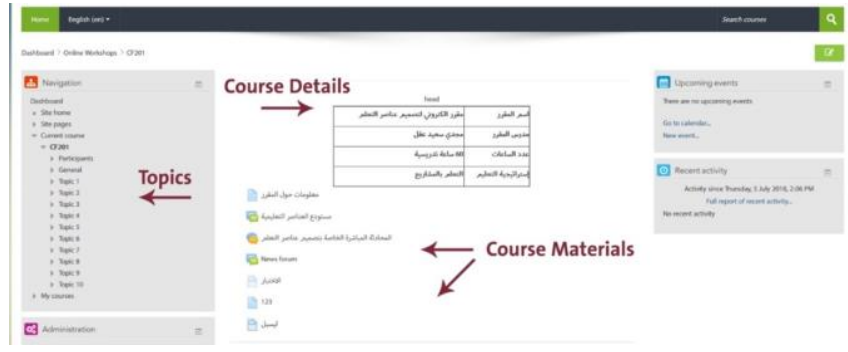

Fig. 3. The main page.

As shown in (Fig. 3), The content of the DL course was arranged on a weekly basis according to the standard book. Accordingly, all the topic contents and materials were provided followed by the activities of the current week. The resources of the course were differed between Power Point presentations, YouTube videos, articles, etc. Hence, all content was shared under each topic column.

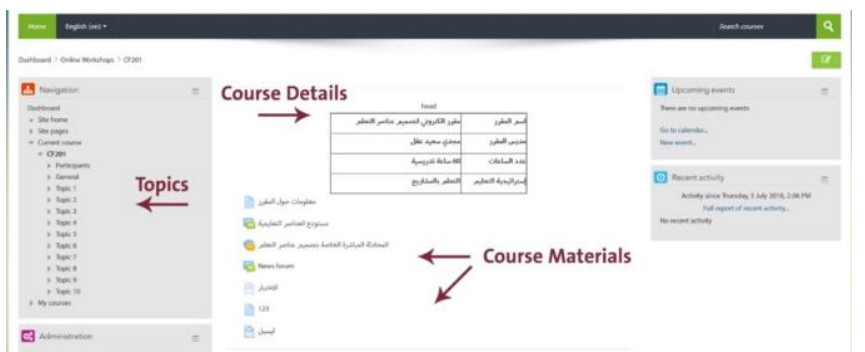

Fig. 4. The course page and subtopics.

The DL course was to be utilized from the second to the ninth week of the semester. Learners were introduced to the course during the first week of the semester, and they were asked to join the discussion platform to break the ice and be familiar with the course as in Fig. 4, discussion platforms. 
Accordingly, the instructor started to introduce the topics of the curriculum, then the instructor demonstrated the usage of the DL course, and the learner was then asked to explore the course individually. The course was designed in a variety of resources and materials (e.g., videos, PowerPoint slides, PDF articles, etc.) based on their major subject.

Moreover, learners were asked individually to participate in the course activities and were given the instruction of the quizzes and the exams of the course. Learners were given three quizzes and a midterm exam (as shown in Fig. 5)

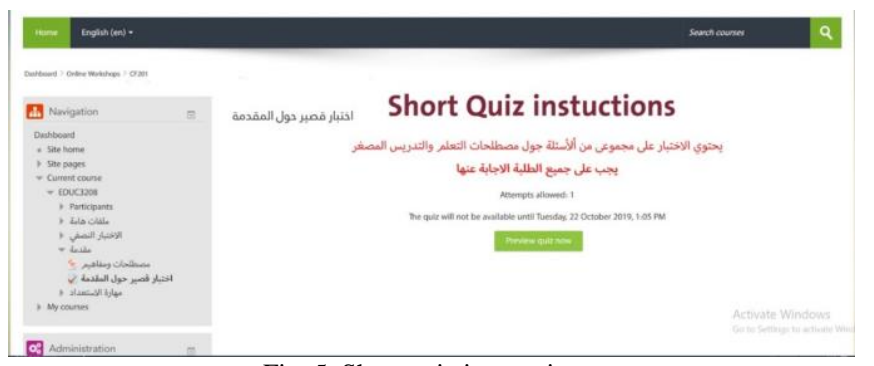

Fig. 5. Short quiz instructions.

\section{Evaluation Phase}

DL Courses can be evaluated for specific evaluation purposes. Evaluation may include learners' reactions, the achievement of learning objectives, the transfer of job-related knowledge and skills, and the impact of the project on the organization. According to Watson [44], evaluation is a constant process that starts from the beginning of the project till the end and consists of four main elements: Reactions, Learnings, Behaviour, Result.

\section{J. Author's Role}

Authors were the designers and the facilitators of this research. From the beginning of this research, the researcher designed the DL course through Moodle system. Accordingly, the lecturer assists learners to understand the meaning of DL during the first week of the semester, where he served as an instructor to guide the learners in their registration on the system. The researcher applied this course with a assistance from the psychology course lecturer, as he played an important role in this course design, guiding the researcher in the course book and materials and other educational aids needed. Therefore, the researcher had to monitor the whole learning process throughout the semester.

\section{K. Learner's Role}

Learners had to meet with the instructor throughout the semester. At the beginning of the semester, they were introduced to the course, and were given the course book and materials and content. The guidelines of the course were discussed clearly by the course instructor along with the learning objectives and outcomes. Simultaneously, an explanation about the DL course and the use of Moodle was then given to the student through the face-to-face meetings, where the learners were encouraged and motivated to demonstrate the use of the Moodle system before the actual intervention took place. Throughout the semester, learners were encouraged to collaborate in the system and discussion platforms.

\section{RESEARCH MethodolOGY}

A qualitative methodology has been implemented in this research to provide comprehensive knowledge and understanding regarding students' online learning experience and how to improve both their academic achievements and satisfaction in DL courses. Two specialists were referred for the validation of the content of the interview. Before data collection, an approval letter regarding the existing research aim has been derived from University College of Applied Sciences - Gaza (UCAS) in connection with the population and sampling. This study has been carried out among undergraduate students who have already had experience with online learning and were e-learning users in the UCAS.

\section{A. Qualitative Data}

To provide a better understanding of DL courses in Palestine, this research has employed a qualitative approach to give an inclusive insight into the developed guidelines on designing DL courses through Moodle system to enhance student's satisfaction and academic achievements in online learning environments.

\section{1) Interviews}

Ten participants were interviewed. The interview group was 3 participants. Note that the group size was usually kept small to control the group easily [16]. In this research, the researcher selected the interviewees purposely; in this way, we could be assured that our sample has some knowledge regarding DL and were therefore able to reflect their own experience towards DL. The interviewees were asked to sit according to a sitting plan during the interview to mix the interviewees evenly based on their performance. Interviews were implemented in this study. Interviews are tools for extracting direct data from participants regarding their details of experience and reflection of meaning [17]. The interview provides the learners with the opportunity to reflect on their research. The interviews were designed in this research to be completed within ninety minutes. The length of the interview had to be set approximately so that it allows the participants to pleasantly reconstruct their experience and put it into the context of their experience. Furthermore, participants need time to reflect on its meaning and this timescale was long enough to make them feel they were being taken seriously. These aspects were vital in the sense of reliability and validity.

All the interviewees were given the consent form to sign before starting the interview, and they could withdraw at any time during the interview process. At the beginning of the interview, the interviewer started by generally introducing the purpose of the interview and to engage the interviewees and make them comfortable. Furthermore, the interview was videotaped, and voice recorded to prevent any data loss. The interview was conducted in Arabic. Moreover, the transcripts were translated to English using (back-to-back) translation technique. The researcher then duplicated and labeled the data. The interviews were then transcribed, then literally translated to English. The transcript was transcribed in a word processing format. Then, the transcript was analyzed to answer the following questions:

- Would you give me an example of the contribution of 
distance learning in the Gaza Strip?

- What are the challenges that you faced during this experiment; did it affect your achievement and satisfaction in any way? If so, how?

- What are the suggestions from your point of view on enhancing the process of DL for a better result?

\section{STUdy RESULTS AND FINDINGS}

In conclusion of this study, without a precise guideline for both students and instructors on how to be part of a DL settings, the goal of the learning process could be impossible to achieve. This study developed a guideline to increase student satisfaction through distance in Palestine which is based on the analysis of student's feedback from this experience. And that is done by designing a DL course through Moodle based on TDT of Moore. The main idea of the TDT is built based on three main variables which are 1) student autonomy or self-regulated student, which refers to student dependency to take their own action and make their own decision that is related to their education experience. 2) the dialogue between DL parties, considered to be a crucial variable in DL settings, simply because there is no face-to-face conversation between the students and their own instructor, thus, DL instructors needs to implement strategies that encourage student-instructor dialogue. And, finally, 3) the DL course structure, which basically depends on the course design and understanding the requirements of individual learners to examine what was to be taught, to describe objectives of learning, activities, to structure learner exercises, evaluations, and the relationship of the instructor and learner. Based on Moore's TDT, these three main variables need to be considered to achieve a high percentage of student satisfaction during DL settings [55].

This investigation provided a definition for DL for Gaza learners which is most needed. Furthermore, in Gaza, where there is lack of technologies, adults continue to seek learning opportunities that provide flexibility and that respond to their immediate learning. Together, many institutions continue to offer more courses through the World Wide Web to save money and time. On the other hand, the course structure type and level that enables adults to learn best in Gaza in online environments have not been adequately investigated before. Although some studies investigated theory of transactional distance proposed by Moore, only a few studies explored both autonomy and structure (or self-regulation), and none investigated how the two effects satisfy the perceived learning of adult learners. Moreover, no studies have been conducted on student autonomy and satisfaction regarding DL in Gaza. Additionally, the suggested guidelines of this study are separated into five main sections, as shown in Fig. 6.

\section{A. Interview Results}

The interviewees commented that, from this experience, they can interact with other participants, irrespective of location and time. The entire process was easy for them, as they had the chance to log into Moodle any time anywhere, except during electricity blackouts. Throughout the interview, a participant declared that he could log in and edit his assignment freely.

Discussion through Moodle allowed the participants to be more flexible regarding the time given to submit their assignments. When they were asked about the contribution of DL in Gaza, participants proposed that learning through distance would give them the opportunity to overcome the siege that the Gaza Strip suffers from, which will allow them to enroll and further their studies through distance.

Accordingly, this experience has enhanced the learner's communication skills and dialogue, as the participants declared that this experience offered them a platform to share and discuss their own ideas with their instructor and other classmates as well. Finally, this experience improved their group work, encouraged them to create togetherness through the Moodle discussing space. A participant further explained that through this experience, learning community could communicate freely without any borders, which is most needed in the Gaza Strip, especially at this time where there is a continuous siege for years.

The interview results revealed that excellent time management had helped the learners to overcome their challenges. Despite a strict timetable, DL enabled them to engage in the learning process whenever they wanted. Accordingly, this new experience had to give them the flexibility to contribute to their own knowledge building by searching and depending on themselves through the learning process. The interviewees commented that this experience had improved their satisfaction in several ways. With the flexibility provided by the DL and Moodle, they have commented that they felt more attached to the learning process. This experience provided them with a platform where they can be more active and collaborative in their own learning process.

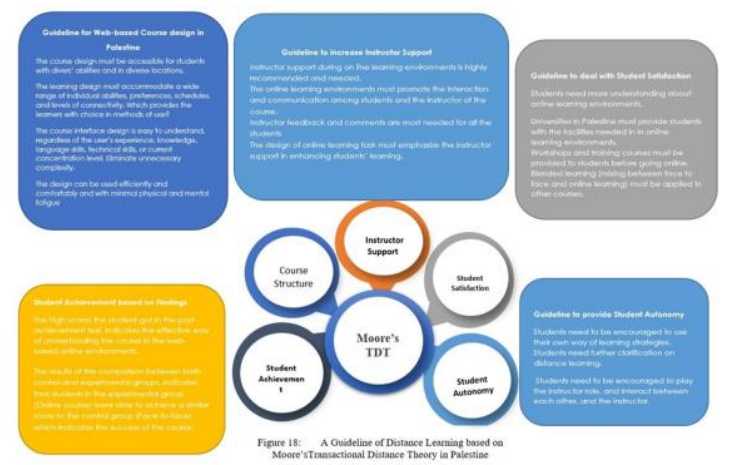

Fig. 6. Guidelines of DL courses based on TDT.

\section{B. Guidelines for DL Course Design in DL Environments Palestine}

Based on the research results and findings, the researcher recommended a few guidelines and considerations for the DL course design in Palestine. It is important for the course developers and instructional designers to consider the course design that must be accessible for students with diverse abilities and in diverse locations. Lastly, the design can be used efficiently and comfortably and with minimal physical and mental fatigue.

1) Guidelines for instructor support and dialogue in $D L$ environments palestine

This study finding showed that instructor support role 
during online learning environments is highly recommended and needed. This implies that instructor has a great role in DL courses for instance, communication with his students, feedback to students' inquiries. Additionally, the online learning environments must promote interaction and communication among students and the instructor of the course (Dialogue). Furthermore, Instructor feedback and comments are most needed for all the students. Lastly, the design of the online learning tasks must emphasize the instructor's support in enhancing students' learning.

2) Guidelines regarding student satisfaction in $D L$ environments Palestine

The results showed that students need more understanding of online learning environments. Accordingly, it is the universities in Palestine's role to provide students with the facilities needed in online learning environments. In addition, workshops and training courses must be provided to students before going online. It is highly recommended that blended learning must be applied in other courses, instead of going fully online, while the students nether the instructors do not have enough experience regarding DL.

\section{3) Guidelines regarding student autonomy in $D L$ environments Palestine}

The results showed that students need to be encouraged to use their own way of learning strategies. Moreover, students need further clarification on DL. And lastly, students need to be encouraged to play the instructor role, and interact with each other, and the instructor.

\section{4) Guidelines regarding student achievement in $D L$} environments Palestine

The result of this study showed that the high scores the student got in the achievement test, which was applied before and after the experiment to measure students' achievement through DL courses, indicate the effective way of understanding the course in the DL online environments. Moreover, the results indicate that students in the Online course were able to achieve a high score which indicates the success of the course.

\section{CONCLUSION}

This research was designed based on the TD theory of Moore. The findings showed that students enjoyed being in something that is not traditional and more flexible regarding the time and place of the study. This research also has implications for theories that undergird the TDT. This research study at this stage has developed a course design based on the TDT of Moore. All the obstacles and challenges of the DL environment illustrated in Moore's work can be found in the DL environment.

The research also provides further evidence that the theory of TD can be applied with consideration. Since its creation in the early 1970s, TD has been applied to a variety of distance education models [31], [32], [55]-[57]. This research study has shown that the learning environment also can be included in furthering Moore's theory. Thus, TDT provides a paradigm for future understanding of digital teacher-to-student relationships.
Finally, this research provides a guideline for a better understanding of TD learning and how to implement the theory to study student satisfaction and autonomy in an online course. The theory used, the course design implementation, and all the facilities needed in online settings must be taken into consideration.

\section{A. Designing a Moodle Environment Context in Palestine in Comparison to Other Countries}

For people living in the Gaza Strip, having Internet access can represent a vital opportunity for connecting with the rest of the world, a way to escape the continuous siege. This is not without its problems, as the Internet connection for the Gaza Strip is provided by an Israeli company and thus is outside of Palestinian control [58].

In Palestine, online learning portals have been used in higher education institutions; however, there are some challenges that need to be investigated, for instance, lack of experience by instructors, lack of background among the students. In this regard, this research attempted to study the ongoing status of DL implementation in Palestinian higher institutions. However, in comparison with the implementation of Moodle in Palestine to other countries like Malaysia, the authors have concluded that Malaysia context regarding using Moodle has been well-prepared for a long time, as they have e-learning experts that are working in their higher institutions For instance, University Teknologi Malaysia (UTM) began e-learning or "Virtual Learning System" in 1997 through "Campus Cyber Program" and developed independent virtual learning websites via a centralized Learning Management System using WebCT Learning Management System in 2001.

In 2005, UTM switched to an open e-learning system and had since continued using it [59]. Besides building and developing an e-learning system for faculties, UTM has concentrated training and updated knowledge and skills for UTM staff on a yearly basis to be updated with the e-learning system. On the other hand, Palestinian higher institutions are still trying to adapt to such technology, as the study findings showed that many young students in Gaza can connect with peers worldwide through personal computers and mobile applications (e.g., Skype, WhatsApp, Snapchat). However, there are certain concerns that need to be investigated and developed for students, instructors, and administrators.

\section{RECOMMENDATIONS FOR FUTURE RESEARCH}

The results of this study shed light on student experience and background regarding DL. In this regard, this study has some recommendations for future research as follows.

First, for administrators of higher institutions in Palestine, to implement DL, there must be more interest given to the facilities needed for students as well as instructor and course developers. Workshops and training sessions must be given for both instructor and students to make them more familiar to take the most advantage of the LMS like Moodle.

Second, further studies in utilizing DL among Palestinian universities must be conducted, as this research was the first attempt to investigate the implementation of DL in a higher institution in Palestine. Additional research in this area would 
extend the understanding of DL implementations in higher institutions.

\section{CONFLICT OF INTEREST}

The authors declare no conflict of interest.

\section{AUTHOR CONTRIBUTIONS}

The authors of this manuscript have worked collaboratively in designing the course, interviewing the participants, constructing the manuscript. Moreover, to write the literature review and discussion. Furthermore, all authors have read and approved the final manuscript.

\section{REFERENCES}

[1] H. Abuhassna, W. M. Al-Rahmi, N. Yahya, M. A. Z. M. Zakaria, A. B. M. Kosnin, and M. Darwish, "Development of a new model on utilizing online learning platforms to improve students' academic achievements and satisfaction," Int. J. Educ. Technol. High. Educ., vol. 17, no. 1-23, 2020.

[2] H. Abuhassna and N. Yahaya, "Students' utilization of distance learning through an interventional online module based on Moore transactional distance theory," Eurasia Journal of Mathematics, Science and Technology Education, vol. 14, no. 7, p. 3043, 3052, 2018.

[3] I. E. Allen, J. Seaman, R. Poulin, and T. T. Straut, "Online report card: Tracking online education in the United States," Babson Survey Research Group and the Online Learning Consortium (OLC), Pearson, and WCET state authorization Network, 2016.

[4] S. Britain and O. Liber, A Framework for Pedagogical Evaluation of Virtual Learning Environments, 1998.

[5] C. Pantel, "A framework for comparing web-based learning environments," Master's thesis, School of Computing Science, Simon Fraser University, Canada, 1997.

[6] M. D. Levi and F. G. Conrad, Usability testing of World Wide Web, 1998.

[7] B. Shneiderman, Designing the User Interface: Strategies for Effective Human-Computer Interactions, 3rd edition, Reading, MA: Addison-Wesley, 1998.

[8] F. A. Azhari and L. C. Ming, "Review of e-learning practice at the tertiary education level in Malaysia," Indian Journal of Pharmaceutical Education and Research, vol. 49, no. 4, pp. 248-257, 2015.

[9] M. Paechter and B. Maier, "Online or face-to-face? Students' experiences and preferences in e learning," Internet and Higher Education, vol. 13, no. 4, pp. 292-297, 2010.

[10] T. Panyajamorn, S. Suthathip, Y. Kohda, P. Chongphaisal, and T. Supnithi, "Effectiveness of E learning design and affecting variables in Thai public schools," Malaysian Journal of Learning and Instruction, vol. 15, no. 1, pp. 1-34, 2018.

[11] W. Horton. (2005). Leading e-learning. ASTD. [Online]. p. 1. Available: http://www.e-learningguru.com

[12] K. Fry, "Forum focus and overview, the business of e-learning: Bringing your organization in the knowledge economy," Telcam Group, University of Technology, Sydney, 2000.

[13] Dublin. (2005). Electronic Journal of E-Learning. [Online]. Available: https://www.ejel.org/

[14] D. G. Oblinger and B. L. Hawkins, "The myth about e-learning," Educause Review, 2005.

[15] European Commission, Communication from the Commission: E-learning-Designing "Tejas at Niit" Tomorrow's Education, European Commission, Brussels, 2000.

[16] L. M. Tseng, J. R. Lin, and P. H. Chen, "Evaluating the effectiveness of e-learning system in uncertainty," Industrial Management \& Data Systems, vol. 111, no. 6, pp. 869-889, 2011.

[17] M. S. Salter, B. Pharm, A. Karia, M. F., Sanfilippo, and M. R. Clifford, "Effectiveness of e-learning in pharmacy education," American Journal of Pharmaceutical Education, vol. 78, no. 4, pp. 1-12, 2014.

[18] S. S. Noesgaard and R. Orngreen, "The effectiveness of e-learning: an explorative and integrative review of the definitions, methodologies and factors that promote e-learning effectiveness," The Electronic Journal of e-Learning, vol. 13, no. 4, pp. 278-290, 2015.

[19] T. Anderson, "Towards a theory of online learning," The Theory and Practice of Online Learning, 2nd Edition, pp. 45-74, Edmonton: Athabasca University Press, 2011.
[20] S. D. Johnson, S. R. Aragon, N. Shaik, and N. Palma-Rivas, "Comparative analysis of learner satisfaction and learning outcomes in online and face-to-face learning environments," Journal of Interactive Learning Research, vol. 11, no. 1, pp. 29-49, 2000.

[21] H. Rosenberg, H. A. Grad, and D. W. Matear, "The effectiveness of computer-aid, self-instructional programs in dental education: A systematic review of the literature," Journal of Dental Education, vol. 67, no. 4, pp. 524-532, 2003

[22] S. Goyal, "E-Learning: Future of education," Journal of Education and Learning, vol. 6, no. 2, pp. 239-242, 2012.

[23] J. Gilbert, S. Morton, and J. Rowley, "E-learning: The student experience," British Journal of Educational Technology, vol. 38, no. 4, pp. 560-573, 2007.

[24] T. E. Welsh, R. C. Wanberg, G. K. Brown, and J. M. Simmering, "E-learning: Emerging uses, empirical results, and future directions," International Journal of Training and Development, vol. 7, no. 4, pp 245-258, 2003.

[25] J. Strother, "An assessment of the effectiveness of e-learning in corporate training programs," International Review of Research in Open and Distance Learning, vol. 3, no. 1, pp. 1-17, 2002.

[26] T. Unwin, Survey of e-learning in Africa, Royal Holloway University of London, 2008.

[27] O. O. Jethro, M. A. Grace, and K. A. Thomas, "E-learning and its effects on teaching and learning in a global age," International Journal of Academic Research in Business and Social Sciences, vol. 2, no. 1, pp. 203-210, 2012.

[28] J. W. Creswell, A Concise Introduction to Mixed Methods Research, Thousand Oaks, CA: Sage, 2015.

[29] I. Seidman, Interviewing as Qualitative Research: A Guide for Researchers in Education and the Social Sciences, 3rd ed. New York: Teachers College Press, 2006.

[30] R. M. Gagne, W. W. Wager, K. C. Golas, and J. M. Keller, Principles of Instructional Design (5 th edition), California: Wadsworth, 2005.

[31] M. Molenda, "In search of the elusive ADDIE model," Perf. Improv., vol. 42, pp. 34-36, 2003.

[32] V. Naganathan and K. C. Wong, "Overview of instructional design model: Issues and challenges," International Journal of Research in Management and Technology, vol. 2, no. 3, pp. 324-333, 2012.

[33] M. G. Moore, "Theory of transactional distance," in D. Keegan (Ed.), Theoretical Principles of Distance Education, pp. 23-37, London: Routledge, 1993

[34] M. G. Moore, Learner Autonomy: The Second Dimension of Independent Learning, 1972.

[35] H. Kang and A. S. Gyorke, "Rethinking distance learning activities: A comparison of transactional distance theory and activity theory," Open Learning: The Journal of Open and Distance Learning, vol. 23, no. 3, 2008.

[36] D. S. Stein et al., "Bridging the transactional distance gap in online learning environments," American Journal of Distance Education, vol 19, no. 2, pp. 105-118, 2005.

[37] J. K. Mbwesa, "Transactional distance as a predictor of perceived learner satisfaction in distance learning courses: A case study of bachelor of education arts program, University of Nairobi, Kenya," Journal of Education and Training Studies, vol. 2, no. 2, pp. 176-188, 2014.

[38] N. Wengrowicz and B. Offir, "Teachers' perceptions of transactional distance in different teaching environments," American Journal of Distance Education, vol. 27, no. 2, pp. 111-121, 2013.

[39] K. C. Ekwunife-Orakwue and T. Teng, "The impact of transactional distance dialogic interactions on student learning outcomes in online and blended environments," Computers \& Education, pp. 78414-427, 2014.

[40] X. Huang, A. Chandra, C. A. DePaolo, and L. L. Immons, "Understanding transactional distance in web-based learning environments: An empirical study," British Journal of Educational Technology, pp. 1-14, 2015.a

[41] A. Kassandrinou, C. Angelaki, and I. Mavroidis, "Transactional distance among Open University students: How does it affect the learning process?" European Journal of Open, Distance and e-Learning, vol. 17, no. 1, pp. 26-42, 2014.

[42] L. A. Flowers, L. O. Flowers, T. A. Flowers, and J. L. Moore, "Examining the effects of online distance education of African American students' perceived learning," Black History Bulletin, vol. 77, no. 1 , pp. 21-26, 2014

[43] T. Rabinovich, "Transactional distance in a synchronous web-extended classroom learning environment," Dissertation Abstracts International Section A, vol. 70, p. 500, 2009. 
[44] Y.-J. Chen, "Dimensions of transactional distance in the World Wide Web learning environment: A factor analysis," British Journal of Educational Technology, vol. 32, no. 4, pp. 459-470, 2001.

[45] R. L. Shearer, "Transactional distance and dialogue: An exploratory study to refine the theoretical construct of dialogue in online learning," Dissertation Abstracts International Section A, vol. 71, p. 800, 2010.

[46] P. Gorsky and A. Caspi, "A critical analysis of transactional distance theory," Quarterly Review of Distance Education, vol. 6, no. 1, pp. $1-11,2005$.

[47] L. Goel, P. Zhang, and M. Templeton, "Transactional distance revisited: Bridging face and empirical validity," Computers in Human Behavior, vol. 28 , no. 4, pp. 1122-1129, 2012.

[48] N. Shin, "Transactional presence as a critical predictor of success in distance learning," Distance Education, vol. 24, no. 1, pp. 69-86, 2003.

[49] J., Kim, Y. Kwon, and D. Cho, "Investigating factors that influence social presence and learning outcomes in distance higher education," Computers \& Education, vol. 7, no. 2, pp. 1512-1520, 2011.

[50] M. A. Tapanes, G. G. Smith, and J. A. White, "Cultural diversity in online learning: A study of the perceived effects of dissonance in levels of individualism/collectivism and The Open University," History of the OU, 2013.

[51] S. Uzuner, "Questions of culture in distance learning: A research review," International Review of Research in Open \& Distance Learning, vol. 10, no. 3, pp. 1-19, 2009.

[52] M. Wang, "Designing online courses that effectively engage learners from diverse cultural backgrounds," British Journal of Educational Technology, vol. 38, no. 2, pp. 294-311, 2007.

[53] J. Hannon and B. D'Neto, "Cultural diversity online: Student engagement with learning technologies," International Journal of Educational Management, vol. 21, no. 5, pp. 418-432, 2007.

[54] D. H. Lim, "Cross cultural differences in online learning motivation," Educational Media International, vol. 41, no. 2, pp. 163-175, 2004.

[55] M. Moore and G. Kearsley, Distance Education: A Systems View, Belmont, CA: Wadsworth, 1996.

[56] Y. Kuo, "Accelerated online learning: perceptions of interaction and learning outcomes among African American students," American Journal of Distance Education, vol. 28, no. 4, pp. 241-252, 2014.

[57] D. F. Waston, "Computing the n-dimensional delaunay tessellation with application to voronoi polytons," The Computer Journal, vol. 24 pp. 167-172, 1981.

[58] H. Tawil-Souri and M. Aouragh, "Intifada 3.0? Cyber colonialism and Palestinian resistance," Arab Studies Journal, vol. 22, no. 1, p. 102, 133, 2014.

[59] N. A. Shukor, Z. Tasir, and H. Meijden, "An examination of online learning effectiveness using data mining," Procedia-Social and Behavioral Sciences, vol. 172, pp. 555-562, 2015.

Copyright ( $\odot 2021$ by the authors. This is an open access article distributed under the Creative Commons Attribution License which permits unrestricted use, distribution, and reproduction in any medium, provided the original work is properly cited (CC BY 4.0).

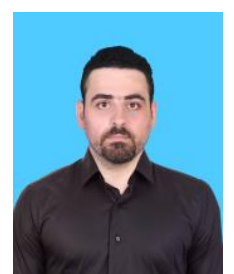

Hassan Abuhassna is currently working as an assistant professor at Universiti Teknologi Malaysia (UTM). Hassan was working in UTM as a postdoc fellowship for six months, in addition to a part-time lecturer for two months. Hassan is a Ph.D. holder in education technology (online learning) with Merit. In addition to a master's degree in Instructional Technology with practical experience. Driven to inspire others to pursue academic and personal excellence, motivated and talented educational technology specialist, specializing in instructional technology web-based courses design. His current research interests include multimedia in education, online learning, and ICT in education.

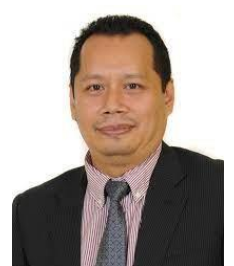

Noraffandy Yahaya received the Ph.D. degree in computer-based learning from the University of Leeds, U.K. He was the head of the Department of Educational Science, Mathematics and Creative Multimedia, for nine years. He has been an associate professor with the Faculty of Education, Universiti Teknologi Malaysia, since 2013 . He has published more than 50 papers in the research area of online learning, ICT in education, and the use of technology in teaching and learning. His current research interests include multimedia in education, online learning, and ICT in education.

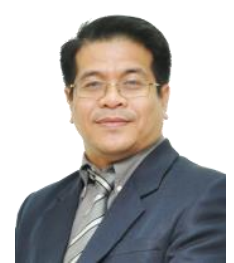

Megat Aman Zahiri Bin Megat Zakaria received the Ph.D. Degree in education technology from the University Teknologi Malaysia, he is the director of Information Technology Manager, and an assistant professor in the Department of Educational Sciences, Mathematics and Multimedia Creative, Faculty of Education, Universiti Teknologi Malaysia, 2009 present. His current research interests include multimedia in education, online learning, and ICT in education.

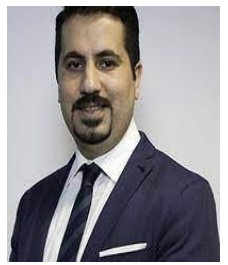

Qusay Al-Maatouk received the Ph.D. degree in Universiti Teknologi Malaysia, He has more than 35 research articles were published in international journals and conferences, He supervised more than 70 undergraduate research projects. Experience in academic and scientific conferences management. Participated in many international conferences as master of ceremony (MC) or as a presenter of research papers such as (13th IEEE SCORED 2015, 2016 3rd MEC, 4th ICIT, 3rd GCMT 2019 3rd AIMC 2019).

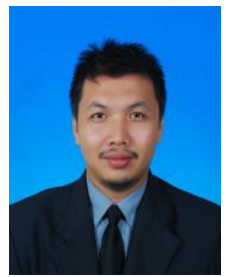

Fareed Awe obtained his Ph.D. from the Faculty of Islamic Contemporary Studies at University Sultan Zainal Abidin (UNISZA) Terengganu in 2018, majoring in Arabic Education (curriculum). He is currently working in UTM as a senior lecturer at the Faculty of Social Sciences \& Humanities, School of Islamic civilizations, Universiti Teknologi Malaysia, Skudai Johor Bharu. 